Article type: Article

\title{
Effect of water content on the corrosiveness of imidazolium-based ionic liquids
}

S. Noori, M.V. Diamanti ${ }^{*}$, MP. Pedeferri, A. Brenna, M. Ormellese

Seyedreza Noori

Politecnico di Milano, Department of Chemistry, Materials and Chemical Engineering "Giulio Natta", Via Mancinelli 7, 20131 Milan, Italy

seyedreza.noori@mail.polimi.it

Maria Vittoria Diamanti

Politecnico di Milano, Department of Chemistry, Materials and Chemical Engineering "Giulio Natta", Via Mancinelli 7, 20131 Milan, Italy

mariavittoria.diamanti@polimi.it

\section{MariaPia Pedeferri}

Politecnico di Milano, Department of Chemistry, Materials and Chemical Engineering "Giulio Natta”, Via Mancinelli 7, 20131 Milan, Italy

mariapia.pedeferri@polimi.it

Andrea Brenna

Politecnico di Milano, Department of Chemistry, Materials and Chemical Engineering "Giulio Natta", Via Mancinelli 7, 20131 Milan, Italy

andrea.brenna@polimi.it

Marco Ormellese

Politecnico di Milano, Department of Chemistry, Materials and Chemical Engineering "Giulio Natta", Via Mancinelli 7, 20131 Milan, Italy

marco.ormellese@polimi.it

Ionic Liquids (ILs) are gaining attention in $\mathrm{CO}_{2}$ absorption, thanks to their favorable

selectivity towards $\mathrm{CO}_{2}$ and physical characteristics, yet their corrosion behavior towards metallic equipment needs deeper evaluation, especially when approaching potential working

conditions. Here we investigate the behavior of carbon steel and stainless steel in imidazolium based ILs with different alkyl chain lengths, mixed with various water contents. Oxygen reduction is identified as cathodic process, with limiting current density affected by fluid 


\section{WILEY-VCH}

viscosity, oxygen solubility and diffusivity. The effect of water on ILs corrosiveness changes with its quantity and depends on the formation of a miscible solution or phase separation. Moreover, dissociation of ILs anions releases fluoride ions in water phase, increasing electrolyte aggressiveness.

Keywords: Imidazolium; Ionic liquids; Oxygen reduction; Polarization; Steel.

\section{Introduction}

$\mathrm{CO}_{2}$ absorption/stripping technology mostly relies on amine-based materials such as monoethanolamine (MEA). [1,2] Despite of MEA's popularity due to its advantageous properties, such as rather high $\mathrm{CO}_{2}$ carrying capacity, fast reaction, low hydrocarbon absorption and availability, [3] some drawbacks of MEA, including high energy demand for absorption/regeneration cycles, high vapor pressure, production of fugitive species, and corrosive interaction with metallic equipment when combined with $\mathrm{CO}_{2},[2,4,5]$ call for the evaluation of new materials as absorption media. [6] As new candidates, ionic liquids (ILs) which are physically selective towards $\mathrm{CO}_{2}$ have been proposed as absorption media. With heats of absorption as low as $-11 \mathrm{~kJ} \mathrm{~mol}^{-1}$, ILs can dramatically reduce the energy demand for regeneration. [7] Ionic liquids can also simultaneously serve to remove $\mathrm{CO}_{2}$ and $\mathrm{SO}_{2}$, which would be an additional benefit. $[8,9]$ Most studies on ILs are focused on finding new applications for this family of materials or modifying the already found ones, such as chemical catalyst, $[10,11]$ heat transfer medium, $[12,13]$ gas absorber, $[8,9]$ lubricant, $[14,15]$ medium for metal electrodeposition, $[16-18]$ and even as corrosion inhibitor. $[19,20]$ However, there is not a conclusive and comprehensive picture on compatibility of ionic liquids with metallic equipment and plant materials in real operating conditions. 


\section{WILEY-VCH}

Studies on corrosion properties of ILs are categorized based on different applications in industry. In the case of solar absorbers, imidazolium-based cations with different alkyl chain lengths and different anions such as $\mathrm{Cl}^{-}, \mathrm{PF}_{6}{ }^{-}$, and bis(trifluoromethylsulfonyl)imide $\left(\mathrm{Tf}_{2} \mathrm{~N}\right)$ have been studied in contact with AISI 1018 carbon steel and AISI 316 stainless steel. [21,22] Aside from the case of ionic liquids containing $\mathrm{Cl}^{-}$, the results showed a good compatibility with steels, with a low corrosion rate $(<15 \mu \mathrm{m} / \mathrm{a})$ in the case of carbon steel and passivity behavior in the case of stainless steel. Perissi et al. [23] reported low corrosion current densities for copper, nickel, brass, AISI 1018 carbon steel and Inconel 600 in presence of $\mathrm{Tf}_{2} \mathrm{~N}$ anion at room temperature, while increasing temperature gave rise to increases in corrosion current densities up to six times in the case of copper, where constituent elements of ionic liquid were detected on the surface of the samples, implying the decomposition of ionic liquids at temperatures higher than $225^{\circ} \mathrm{C}$. [24]

Qu et al. [25] evaluated the corrosive effects of imidazolium and ammonium based ILs, proposed as lubricants, [26] on AISI 52100 carbon steel and 6061-T6 aluminum alloy. Results for both alloys showed the gradual passivation of the metal alloys. Generally, aluminum alloys have shown good corrosion compatibility in neat alkylimidazolium based ionic liquids.

$\mathrm{CO}_{2}$ absorption is also a hot area, as already mentioned. Molchan et al. [28] found that in the presence of alkylimidazolium/tricyanomethanide ionic liquids, surface MnS inclusions in mild steel dissolve in the medium, accompanied by dissolution of surroundings. They also observed lower corrosiveness in ILs having cations with longer chain length. Further studies showed lower corrosiveness of ILs containing lower amounts of dissolved oxygen. [29] The presence of water in ILs also affects the corrosion properties of ILs: while the addition of small amounts of water up to $250 \mathrm{ppm}$ to imidazolium and ammonium based ionic liquids increases corrosion rates considerably, [30] using completely dehydrated ILs in contact with 


\section{WILEY-VCH}

stainless steel can be detrimental, as in absence of water and oxygen the passive film may gradually degrade. [7] In this sense, water content acquires a particularly important role, but most of the studies performed up to this moment do not take this aspect into the necessary consideration. This is particularly true for applications like carbon capture and storage (CCS), where ionic liquids are not expected to work in a dehydrated environment, and therefore water can play a major role.

In this work, which considers a previous screening work on different ILs corrosiveness as starting point, [5] we evaluated the effect of IL water content on the corrosion behavior of carbon steel and stainless steel in contact with three alkylimidazolium based ionic liquids, with the same anion $\mathrm{PF}_{6}{ }^{-}$and different cationic alkyl chain lengths.

\section{Materials and methods}

Three imidazolium-based ionic liquids were purchased from Io.Li.Tec GmbH, with declared purity higher than $99 \%$ and water content lower than 190 ppm:

- 1-butyl-3-methylimidazolium hexafluorophosphate [C4C1 Im][PF6] (C4 hereon)

- 1-hexyl-3-methylimidazolium hexafluorophosphate [C6C1 Im][PF6] (C6 hereon)

- 1-octyl-3-methylimidazolium hexafluorophosphate [C8C1Im][PF6] (C8 hereon) The molecular structures and physical properties of ionic liquids are mentioned in the previous work. [5] To study the effect of ILs water content on corrosion rate, tests were performed in three conditions:

- "equilibrium condition": after 24 hours of exposure to ambient atmosphere, during which the ILs equilibrated their oxygen and humidity content with the surrounding atmosphere; the water uptake was previously observed to depend on the IL anion mostly, and the final water content was in the order of $1.5 \%$ by volume 
- "solubility limit condition": with the addition of deionized water in quantity equal to solubility limit of water in each selected IL at $60^{\circ} \mathrm{C}$ (Table 1)

- "excess of water" condition: a 1:3 volume ratio mixture of deionized water and IL was prepared.

The solubility limits of water in ILs at $60^{\circ} \mathrm{C}$ were adopted from the work by Freire et al. [31] Table 1 shows the corresponding volume percentage of deionized water added to each ionic liquid.

The conductivity of the electrolytes in the different conditions of water content were measured in laboratory and compared with those of both deionized water and tap water. To evaluate the corrosion effect of ionic liquids, one carbon steel (CS) and one stainless steel (SS) in the form of wire with diameters 1.5 and $1 \mathrm{~mm}$, respectively, were tested. Table 2 shows the chemical composition of the two steels.

$<$ Table 1>

$<$ Table 2>

The corrosiveness of ILs was evaluated by performing anodic and cathodic potentiodynamic polarization in the electrolytes of interest. Due to the high price of ILs and difficulty of regeneration and purification of ILs after electrochemical tests, instead of ASTM G5 specifications, [32] a Pyrex cell with a volume in the order of milliliters (mini cell), with some provisions for inlet and controlling apparatus, was used. To check the validity of the setup, some pilot tests were run in both standard ASTM G5 and mini cell in $35 \mathrm{~g} \mathrm{l}^{-1} \mathrm{NaCl}$ aqueous solution (data not shown). All potentiodynamic tests on ionic liquids were performed at $60^{\circ} \mathrm{C}$ as a representative temperature for $\mathrm{CO}_{2}$ capture processes. Heating was achieved by a Velp Scientifica Arex heating magnetic stirrer. To achieve a more uniform heat distribution in the cell, the baine marie method was utilized. 


\section{WILEY-VCH}

To have a reliable control over the exposed surface area of the steel working electrodes (WE), wires were cut into $15 \mathrm{~cm}$-long pieces and coated with resin, in a way that only the metal tip would be in contact with the electrolyte. Before each test, the WEs were ground, using successively finer $\mathrm{SiC}$ abrasive papers up to 1200 grit. Then they were rinsed in deionized water and dried. The polishing quality was studied under a Wild Heerbrugg M8 stereomicroscope and stereographs were obtained using a Leica DFC 290 imaging system. Cathodic tests were performed using a platinum electrode as WE. The electrode is a glass tube of diameter $6 \mathrm{~mm}$, with a platinum sphere tip of $2.15 \mathrm{~mm}$ diameter.

As counter electrode (CE), $1 \mathrm{~mm}$ diameter wire of activated titanium was used. To measure the potential difference between $\mathrm{CE}$ and WE, an Ag wire with pressed and sintered cylindrical $\mathrm{AgCl}$ tip (diameter $1.5 \mathrm{~mm}$, length $4 \mathrm{~mm}$ ) purchased from A-M Systems was used as reference electrode (RE). The reliability of this electrode readings was tested in a standard cell, by comparing it with a standard $\mathrm{Ag} / \mathrm{AgCl} / \mathrm{Saturated} \mathrm{KCl}$ reference electrode.

For anodic and cathodic potentiodynamic tests, a Metrohm Autolab PGSTAT30 potentiostat/galvanostat was used. Before the test, samples were immersed in the electrolyte for one hour, during which the open circuit potential (OCP vs $\mathrm{Ag} / \mathrm{AgCl}$ ) was recorded. In all cases, a negligible potential variation was reached at the end of this monitoring period, and the test could then start. In anodic tests the scan started from $-100 \mathrm{mV}$ with respect to OCP, and continued until $+400 \mathrm{mV}$ OCP, with $10 \mathrm{mV} \mathrm{min}^{-1} \mathrm{scan}$ rate. For this reason, anodic curves may be displayed in slightly different ranges of potential, depending on the OCP reading of each material and condition; yet, in all cases curves are shown in a potential window representative of their behavior in the full range interest. Cathodic polarization tests ranged from $+100 \mathrm{mV}$ OCP to the potential at which a vertical asymptote was reached, which is representative of achieving a limiting current density of the cathodic process. 


\section{WILEY-VCH}

A final stereoscope imaging was conducted after potentiodynamic test to check the samples surfaces.

When clearly active conditions were observed, corrosion rate was calculated by linear polarization resistance, with potential scan from $-10 \mathrm{mV}$ OCP up to $+10 \mathrm{mV}$ OCP with 10 $\mathrm{mV} \min ^{-1}$ scan rate. To evaluate the corrosion rate of carbon steel in such condition, linear polarization tests were also performed to measure polarization resistance, $\mathrm{R}_{\mathrm{p}}$. Corrosion rate can be calculated as given below:

C. $\mathrm{R}[\mathrm{mm} / \mathrm{a}]=1.17\left[\frac{(\mathrm{m} / \mathrm{a})}{\left(A / \mathrm{m}^{2}\right)}\right] \times \frac{0.026[\mathrm{~V}]}{\mathrm{R}_{\mathrm{P}}\left[\Omega \cdot \mathrm{m}^{2}\right]}$

where coefficients 1.17 and $0.026 \mathrm{~V}$ are the ratio of corrosion rate to current density and Stern-Geary constant for active steel, respectively. [33]

\section{Results}

\subsection{Conductivity measurements}

Results of electrolyte conductivity analyses are reported in Table 3. The main consideration emerging is an increase in conductivity with decreasing alkyl chain length. Moreover, in all cases the addition of water increases conductivity to a relevant extent, especially that of the least conductive electrolytes; when water solubility limit is reached and exceeded, conductivity does not increase any more, since the further addition of water separates above the IL, creating a two-phase mixture.

Finally, all electrolytes are more conductive than deionized water (DI) - at least one order of magnitude higher - and to exhibit a conductivity close to, or in most cases higher than, tap water. Therefore, no specific effect related to a relevant ohmic drop is expected to influence potentiodynamic tests.

$<$ Table $3>$ 


\subsection{Potentiodynamic tests in equilibrium condition}

\subsubsection{Cathodic polarization tests}

Potentiodynamic polarization tests were performed after a $1 \mathrm{~h}$ equilibration period of the metal in the chosen solution, during which the metal open circuit potential (OCP) was recorded. In all cases investigated, in the given time frame the metal acquired a stabilization in potential that allowed to perform the test from a reliable starting value of OCP.

Figure1 shows the results of cathodic potentiodynamic tests on Pt electrode in ionic liquids from $\mathrm{C} 4$ to $\mathrm{C} 8$ subjected to atmospheric temperature and humidity (i.e. equilibrium condition); a test performed in deionized (DI) water is also presented, for comparison. In all cases, a limiting current density was reached, allowing to assume that a diffusion process is the rate determining step in cathodic reactions in ILs, like in water. Therefore, oxygen reduction was considered to be the cathodic process, and this assumption was checked by calculating the expected limiting current density in ILs. As known, in stagnant conditions the limiting current density of oxygen reduction, which determines the values of current observed in the vertical asymptote of the cathodic curve, may be estimated as follows (Equation 2):

$i_{L}=\frac{4 F D\left[\mathrm{O}_{2}\right]}{\delta}$

where $F$ is the Faraday constant $\left(\sim 96500 \mathrm{~s} \mathrm{~A} \mathrm{~mol}^{-1}\right), D$ is oxygen diffusion coefficient $\left(\mathrm{m}^{2} \mathrm{~s}^{-}\right.$

$\left.{ }^{1}\right),\left[\mathrm{O}_{2}\right]$ is oxygen concentration $\left(\mathrm{mol} \mathrm{m}^{-3}\right)$, and $\delta$ is the limiting diffusion layer thickness $(\mathrm{m})$. Oxygen diffusion coefficient in $\mathrm{C} 4$ at room temperature is reported to be $2.2 \times 10^{-10} \mathrm{~m}^{2} \mathrm{~s}^{-1}$ [34] while that of water is $1.8 \times 10^{-9} \mathrm{~m}^{2} \mathrm{~s}^{-1}$ at $20^{\circ} \mathrm{C}$. [35] Oxygen solubility in $\mathrm{C} 4$ at $20^{\circ} \mathrm{C}$ is reported as $3.6 \times 10^{-3} \mathrm{M}$, [34] while oxygen molar fraction in fresh water at $20^{\circ} \mathrm{C}$ is in the order of $10^{-5}$. According to Equation 2 and oxygen solubility and diffusion coefficient values discussed, the limiting current density of oxygen in ILs should be 1 to 2 orders of magnitude higher than that of water, considering same limiting diffusion layer thickness in water and in ILs. However, this assumption is not realistic given the higher viscosity of ILs that should increase $\delta$, 
therefore the expected limiting current density in ILs should be lower. On account of these considerations, the slight increase in oxygen limiting current density observed in ILs compared with that shown in deionized water looks justifiable.

\subsubsection{Anodic polarization tests}

Concerning the results of anodic polarization tests in equilibrium condition, i.e., with the lowest water amount considered in this study, our previous work [5] showed open circuit potential of CS in the ILs is several hundreds of $\mathrm{mV}$ higher than that observed in deionized water, suggesting higher nobility of carbon steel in ionic liquid with respect to deionized water. As for stainless steel UNS S31600, the passive behavior with lower corrosion current densities recorded in ILs suggested higher corrosion resistance of stainless steel in such electrolyte compared to deionized water. In addition, corrosion current density was observed to decrease with increasing alkyl chain length, which attests a beneficial effect of ILs with larger cations.

$<$ Figure 1 $>$

Figure 2 shows results of anodic potentiodynamic tests in equilibrium condition IL and in deionized water on stainless steel UNS S30400. The lower corrosion current densities of stainless steel in ILs suggest again an increased corrosion resistance. In addition, the passive behavior expected from stainless steels can be observed, with current density decreasing with increasing alkyl chain length. Open circuit potentials (OCPs) of stainless steel in the ILs considered range from -300 to $-25 \mathrm{mV}$ vs $\mathrm{Ag} / \mathrm{AgCl}$. In this case, no apparent relation between the type of ionic liquid or alkyl chain length and OCP is distinguishable.

$<$ Figure 2 $>$ 


\section{WILEY-VCH}

\subsection{Anodic potentiodynamic tests in presence of water up to its solubility limit}

Figure 3 shows the results of anodic potentiodynamic tests on carbon steel in ILs containing deionized water up to their solubility limit, performed at $60^{\circ} \mathrm{C}$, and in pure deionized water for comparison. Carbon steel OCP is nobler in ILs than in deionized water in all cases, yet it shows a decreasing trend with increasing cation alkyl chain length from $\mathrm{C} 4$ to $\mathrm{C} 8$ : values are 460, -640 , and $-790 \mathrm{mV}$ vs $\mathrm{Ag} / \mathrm{AgCl}$, respectively. Moreover, carbon steel suffers corrosion in such condition of water content in ILs with a very high corrosion current density, close to $0.01 \mathrm{~A} / \mathrm{cm}^{2}$. Above this value, a vertical asymptote in current density is observed, which can be ascribed to a diffusion kinetic control process, owing to the large accumulation of corrosion products in a small electrolyte volume and to their difficult diffusion away from the metal surface.

$<$ Figure 3 $>$

Figure 4 shows the stereographs of carbon steel samples before and after tests in water solubility limit ILs. All samples have undergone general corrosion. A rather uniform thickness reduction can be detected in the three samples, since no peculiar morphological feature is revealed after the attack.

$<$ Figure 4>

$<$ Table 4>

Table 4 shows the measured data and corrosion rates calculated by Equation 1. Results are in good agreement with Figure 3. Corrosion rate increases with alkyl chain length of imidazolium cation. 


\section{WILEY-VCH}

It is now worth to make a comparison between current results and what observed in ILs with lower water content, specifically, in equilibrium with atmospheric conditions due to atmospheric humidity uptake, as emerged from previous work. In Figure 5 we report the anodic curves recorded in $\mathrm{C} 4$, to give a clearer comparison; same considerations apply to all alkyl chain lengths considered. Comparing water content, after exposure to atmospheric temperature and humidity, water in $\mathrm{C} 4$ was reported to be approximately $0.3 \mathrm{vol} \%$. On the other hand, in this work, water content of the $\mathrm{C} 4$ is $4.46 \mathrm{vol} \%$, more than one order of magnitude higher. The addition of water has shifted the anodic curve of carbon steel towards lower potential, and increased the corrosion current by nearly two orders of magnitude.

$<$ Figure 5 $>$

Figure 6 shows the results of anodic potentiodynamic tests on stainless steel in ILs with water content up to their solubility limit and in deionized water at $60^{\circ} \mathrm{C}$. An unexpected effect, which was not observed in dry ILs or at lower water content, is the formation of a nose in the anodic part of polarization curve in $\mathrm{C} 6$ and $\mathrm{C} 8$. After reaching this nose, the current density decreases nearly by two orders of magnitude. This nose can be attributed to a combined formation of a passive layer and steric effect of alkyl chain on the surface, which avoids an effective contact between electrolyte and metal surface. The first hypothesis implies that stainless steel was only weakly passive, if not at all, before the test started, although the material was allowed several days to repassivate after mechanical polishing, as confirmed by the typical passive behavior observed at lower IL water content. If both mechanisms passivation and steric effect - are actually present, the IL itself or water contained in it should at least weaken the stainless steel passive film during the 1 hour long equilibration time, before the test started. An explanation for the increased aggressiveness of the electrolyte in presence of this increased quantity of water is given in the discussion section - paragraph 4, 


\section{WILEY-VCH}

where all three water content conditions are taken into account. Figure 7 shows the stereographs of the stainless steel samples in water solubility limit ionic liquids, where a general corrosion attack is clearly visible on stainless steel in all ILs considered.

$<$ Figure 6>

$<$ Figure $7>$

\subsection{Potentiodynamic tests in excess water condition}

Figure 8 shows the anodic polarization of stainless steel UNS S30400 in ionic liquids to which deionized water in excess with respect to their solubility limit was added, specifically, in a 1:3 water:IL volume ratio, obtaining a water content almost one order of magnitude higher than water solubility limit (see Table 1).

$<$ Figure $8>$

Open circuit potential in these ILs mixtures is still higher than that measured in deionized water, varying from -160 to $30 \mathrm{mV}$ vs $\mathrm{Ag} / \mathrm{AgCl}$; chain length does not show a direct correspondence with the value of open circuit potential. The behavior shown by the metal is discussed in the following paragraph, in comparison with that observed in the other electrolytes considered.

Figure 9 illustrates the stereographs of stainless steel samples before and after the anodic potentiodynamic tests, showing a mild-to-negligible extent of corrosion, with few localizedlike corrosion features.

$<$ Figure 9 $>$ 


\section{WILEY-VCH}

\section{Discussion}

As previously observed, carbon steel suffers corrosion in ILs unless these are kept in dry conditions, or contain very low amounts of water - reasonably not more than what they typically absorb from the atmosphere. Conversely, stainless steel presents a different behavior. A first peculiarity is noticed in $\mathrm{C} 4$, where it preserves its passivity in all IL conditions tested, while this is not true in the other ILs (C6 and C8), where a more complicated trend is observed, as explained in the following.

Figure 10 compares the results obtained on stainless steel in one same ionic liquid, C6, in the different conditions of water content in order to have a clearer understanding of the effect of water on its corrosiveness. Same trend is observed in C8.

Polarization curves are shifted towards higher current densities when water is added to the IL on purpose. Even though in small quantities, the presence of water has dramatic impact on the corrosion resistance of stainless steel in ionic liquids, which is coherent with what observed on carbon steel. Yet, it does not seem to follow a monotonic trend with water concentration: it increases when water is increased from that absorbed by the IL in equilibrium with the atmosphere reaching water solubility, but after that, with addition of more water, corrosion rate, as estimated by the current density in the passive range, decreases. Therefore, a mechanism was hypothesized to justify this trend in corrosiveness, which cannot be ascribed to a simple increase in oxygen content due to the presence of only few percent of water. In presence of an excess of water a two-phase medium is produced, consisting of the clear yellow ionic liquid, containing dissolved water, at the bottom of the cell and water on the top. Acidification may occur due to the release of $\mathrm{F}^{-}$ions in the electrolyte as a product of ILs anion $\left(\left[\mathrm{PF}_{6}\right]^{-}\right)$decomposed in water: if a single phase is present (total miscibility, up to water solubility limit in the IL considered) $\mathrm{F}^{-}$ions are in direct contact with the metal, leading to high corrosion rates, while in presence of an excess of water these anions may move to the 


\section{WILEY-VCH}

water phase that separates on top of the IL, leaving a bottom phase consisting of ionic liquid with lower acidity, $[36,37]$ as schematized in Figure 11. Since the working electrode is dipped in the IL bottom phase and, thanks to the polymeric resin, does not perceive the acidic water phase above, the expected corrosion rate would be then in between that observed in ILs with equilibrium water and that in ILs saturated with water (worst condition), as in fact was noticed.

This hypothesis is supported by experimental evidence:

- the $\mathrm{pH}$ of the water phase that forms on top of ILs in the presence of an excess of water with respect to their solubility limit decreased to $4 \div 5$, confirming its acidification;

- in the same water phase the content of fluoride ions was measured and found equal to $2200 \mathrm{ppm}$, which is more than sufficient to induce localized corrosion especially on UNS S30400 stainless steel;

- indeed, on stainless steel a localized attack was observed in ILs with relevant water content, which may be associated with the large fluoride content in the dissolved water and therefore in contact with the steel surface.

$<$ Figure 10 $>$

$<$ Figure 11 $>$

\section{Conclusions}

The corrosion behavior of carbon steel and stainless steel in ILs suitable as solvents for carbon dioxide capture and storage, as a promising substitutes for currently used amine-based materials, was investigated. Imidazolium based ionic liquids (with three different alkyl chain lengths 4,6 , and 8$)$ and the same anion $\left(\mathrm{PF}_{6}{ }^{-}\right)$were characterized with three different water 


\section{WILEY-VCH}

contents, from simple equilibrium with the atmosphere to an excess of water with respect to their solubility limit. The results show that:

1. The cathodic reaction in imidazolium-based ionic liquids was confirmed to be oxygen reduction, with different limiting current density with respect to water due to different solubility and diffusion parameters for oxygen, as well as different viscosity of the electrolyte.

2. Carbon steel shows a poor corrosion resistance in ILs containing water in higher content with respect to the simple water uptake from air humidity. Due to the hydrolysis of the $\mathrm{PF}_{6}-$ anion, the presence of water in the IL can cause electrolyte acidification, which becomes very corrosive to materials and equipment. Yet, in presence of dry IL - or containing very small content of water, simply due to humidity uptake - corrosion can be reduced by a shielding effect given by ionic liquid interacting with, and likely adsorbing on, the steel surface.

3. The corrosion rate of stainless steel UNS S30400 in water-free IL is up to two orders of magnitude lower than that in ILs containing water up to their solubility limit, where the formation of a nose in the anodic polarization of stainless steel was evidenced. This nose formation could be due to synergic effect of passive layer formation and inhibition effects of the IL cation by steric effects of the alkyl chain.

The presence of an excess of water in the IL, exceeding its solubility limit, gives the formation of a two-phase medium. The acidification produced by IL anions hydrolysis could follow the separation of water on top of the IL, so that the acidity in the IL phase is reduced, together with the corrosiveness of the IL phase, while it increases the corrosion risk in regions in contact with water. 


\section{WILEY-VCH}

\section{References}

[1] A.A. Olajire, Energy 2010, 35, 2610.

[2] J.C.M. Pires, F.G. Martins, M.C.M. Alvim-Ferraz, M. Simoes, Chem. Eng. Res. Des. 2011, 89, 1446.

[3] J.L. Anthony, S.N.V.K. Aki, E.J. Maginn, J.F. Brennecke, Int. J. Environ. Technol. Manag. 2004, 4, 105.

[4] J. Kittel, R. Idem, D. Gelowitz, P. Tontiwachwuthikul, G. Parrain, A. Bonneau, Energy Procedia 2009, 1, 791.

[5] M.V. Diamanti, U.V. Velardi, A. Brenna, A. Mele, M. Pedeferri, M. Ormellese, Electrochim. Acta 2016, 192, 414.

[6] M. Hasib-ur-Rahman, H. Bouteldja, P. Fongarland, M. Siaj, F. Larachi, Ind. Eng. Chem. Res. 2012, 51, 8711.

[7] D.M. D’Alessandro, B. Smit, J.R. Long, Angew. Chemie - Int. Ed. 2010, 49, 6058.

[8] C.A. Faúndez, J.F. Díaz-Valdés, J.O. Valderrama, Fluid Phase Equilib. 2014, 375, 152.

[9] Z. Lei, C. Dai, B. Chen, Chem. Rev. 2014, 114, 1289.

[10] C.M. Maroneze, G.P. dos Santos, V.B. de Moraes, L.P. da Costa, L.T. Kubota, Biosens. Bioelectron. 2016, 77, 746.

[11] P. Zhang, Y. Liu, M. Fan, P. Jiang, Renew. Energy 2016, 86, 99.

[12] N.J. Bridges, A.E. Visser, E.B. Fox, Energy and Fuels 2011, 25, 4862.

[13] H. Chen, Y. He, J. Zhu, H. Alias, Y. Ding, P. Nancarrow, C. Hardacre, D. Rooney, C. Tan, Int. J. Heat Fluid Flow 2008, 29, 149.

[14] A. Hernández Battez, M. Bartolomé, D. Blanco, J.L. Viesca, A. Fernández-González, R. González, Tribol. Int. 2016, 95, 118.

[15] A.E. Jiménez, M.D. Bermúdez, Tribol. Lett. 2007, 26, 53. 


\section{WILEY-VCH}

[16] S.Z. El Abedin, F. Endres, Acc. Chem. Res. 2007, 40, 1106.

[17] F. Liu, Y. Deng, X. Han, W. Hu, C. Zhong, J. Alloys Compd. 2016, 654163.

[18] W. Simka, D. Puszczyk, G. Nawrat, Electrochim. Acta 2009, 54, 5307.

[19] A. Bousskri, A. Anejjar, M. Messali, R. Salghi, O. Benali, Y. Karzazi, S. Jodeh, M. Zougagh, E.E. Ebenso, B. Hammouti, J. Mol. Liq. 2015, 211, 1000.

[20] E. Kowsari, M. Payami, R. Amini, B. Ramezanzadeh, M. Javanbakht, Appl. Surf. Sci. 2014, 289, 478.

[21] M.F. Arenas, R.G. Reddy, J. Min. Metall. Sect. B Metall. 2003, 39, 81.

[22] R.G. Reddy, Z. Zhang, M.F. Arenas, D.M. Blake, High Temp. Mater. Process. 2003, $22,87$.

[23] I. Perissi, U. Bardi, S. Caporali, A. Lavacchi, Corros. Sci. 2006, 48, 2349.

[24] U. Bardi, S.P. Chenakin, S. Caporali, A. Lavacchi, I. Perissi, A. Tolstogouzov, Surf. Interf. Anal. 2006, 38, 1768.

[25] J. Qu, J.J. Truhan, S. Dai, H. Luo, P.J. Blau, Tribol. Lett. 2006, 22, 207.

[26] F. Zhou, Y. Liang, W. Liu, Chem. Soc. Rev. 2009, 38, 2590.

[27] M.D. Bermúdez, A.E. Jiménez, G. Martínez Nicolás, Appl. Surf. Sci. 2007, 253, 7295.

[28] I.S. Molchan, G.E. Thompson, P. Skeldon, R. Lindsay, J. Walton, E. Kouvelos, G.E. Romanos, P. Falaras, A.G. Kontos, M. Arfanis, E. Siranidi, L.F. Zubeir, M.C. Kroon, J. Klöckner, B. Iliev, T.J.S. Schubert, RSC Adv. 2015, 5, 35181.

[29] I.S. Molchan, G.E. Thompson, R. Lindsay, P. Skeldon, V. Likodimos, G.E. Romanos, P. Falaras, G. Adamova, B. Iliev, T.J.S. Schubert, RSC Adv. 2014, 4, 5300.

[30] M. Uerdingen, C. Treber, M. Balser, G. Schmitt, C. Werner, Green Chem. 2005, 7, 321.

[31] M.G. Freire, L.M.N.B.F. Santos, A.M. Fernandes, J.A.P. Coutinho, I.M. Marrucho, Fluid Phase Equilib. 2007, 261, 449. 


\section{WILEY-VCH}

[32] ASTM standard G5, 2013, Standard reference test method for making potentiodynamic anodic polarization measurements, In: Annual book of ASTM standards, vol. 03.02, ASTM international, west Conshohocken, PA, 2013, doi: $10.1520 / \mathrm{G} 0005$.

[33] M. Stern, A.L. Geary, J. Electrochem. Soc. 1957, 104, 56-63.

[34] I.M. AlNashef, M.L. Leonard, M.C. Kittle, M.A. Matthews, J.W. Weidner, Electrochem. Solid-State Lett. 2001, 4, D16.

[35] P. Han, D.M. Bartels, J. Phys. Chem. 1996, 100, 5597.

[36] P.J. Dyson, T.J. Geldbach, Metal catalysed reactions in ionic liquids, Springer, Dordrecht 2005.

[37] S. Carda-Broch, A. Berthod, D.W. Armstrong, Anal. Bioanal. Chem. 2003, 375, 191. 


\section{FIGURES}

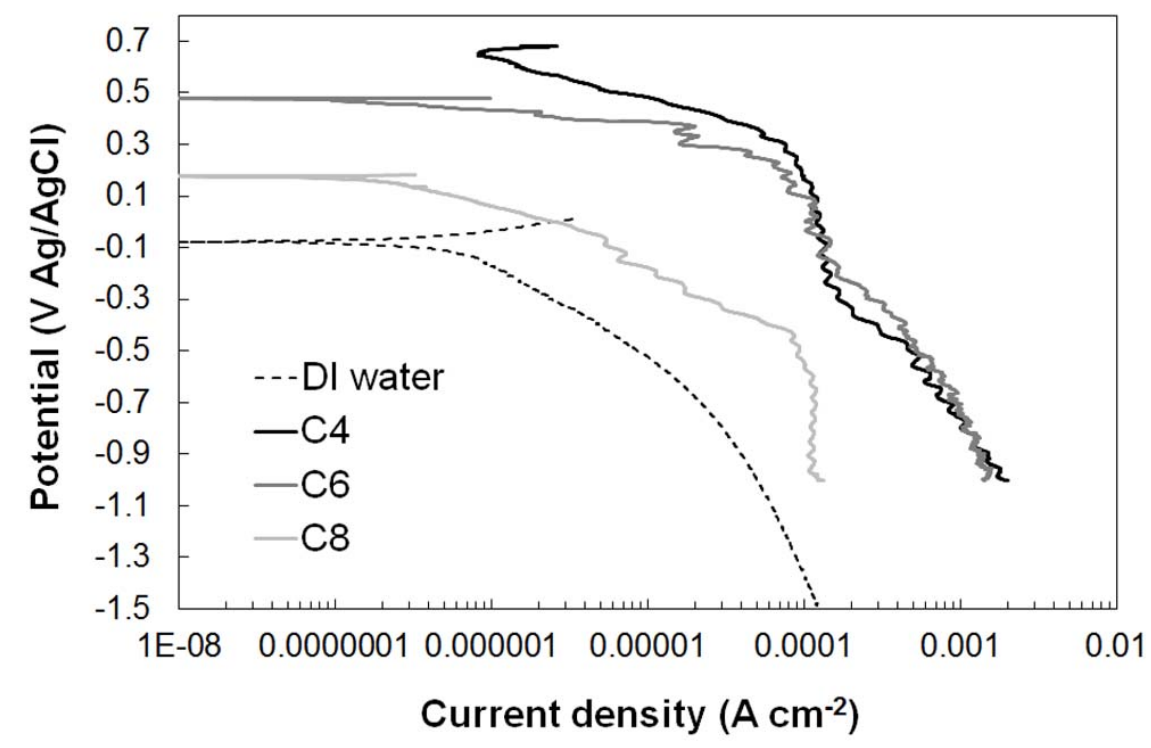

Figure 1. Cathodic potentiodynamic tests in ILs in equilibrium with the atmosphere and in deionized water, on Pt electrode

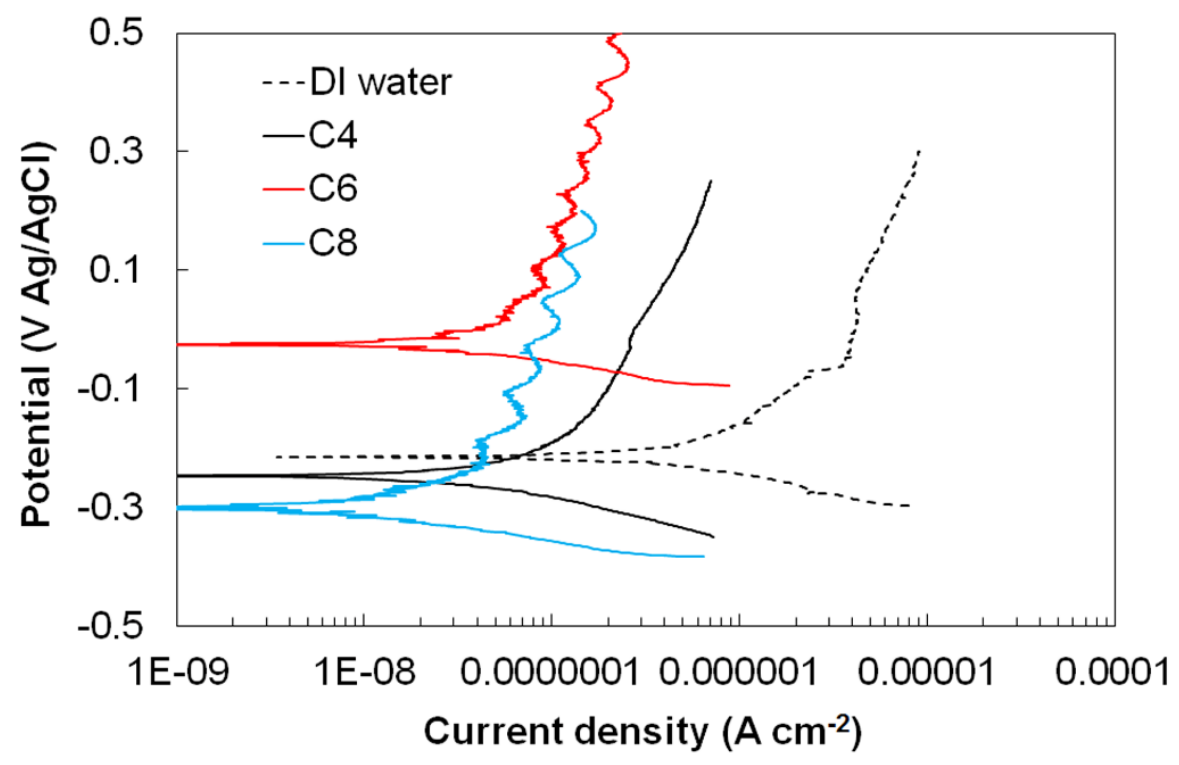

Figure 2. Anodic behavior of stainless steel UNS S30400 in ILs exposed to atmosphere and in deionized water, at $60^{\circ} \mathrm{C}$ 


\section{WILEY-VCH}

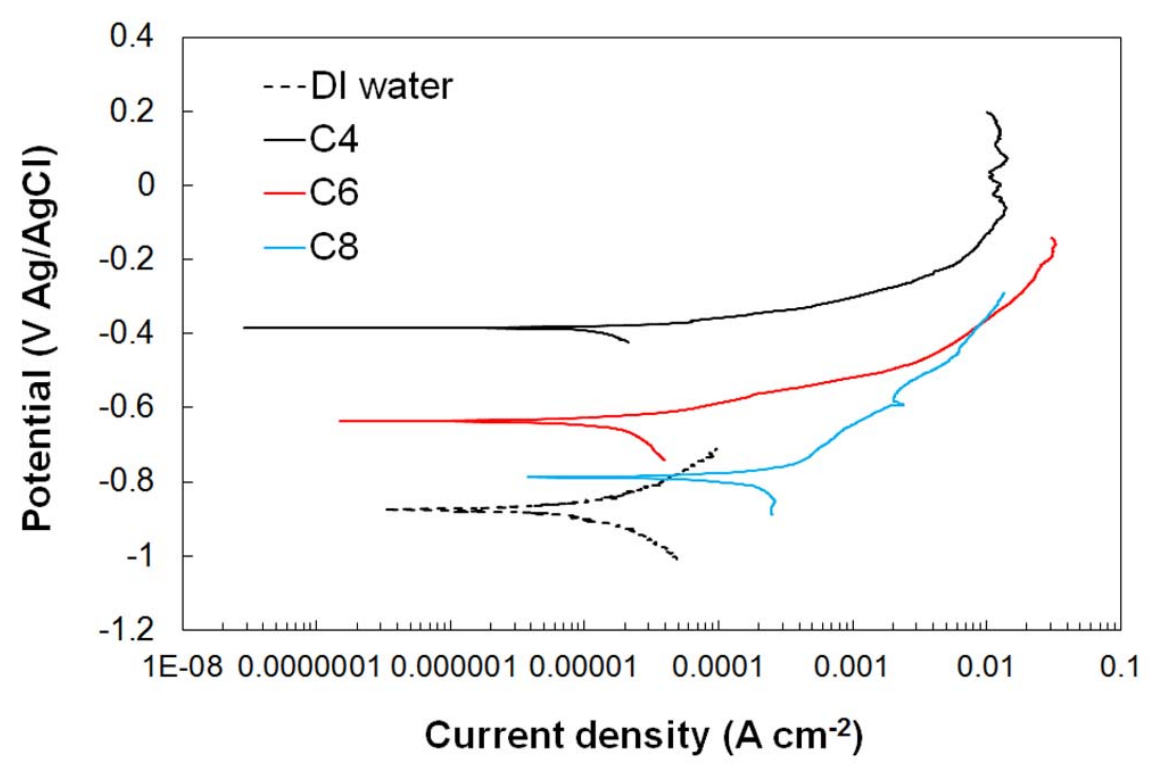

Figure 3. Anodic behavior of carbon steel in ILs containing water up to their solubility limit and in deionized water, at $60^{\circ} \mathrm{C}$

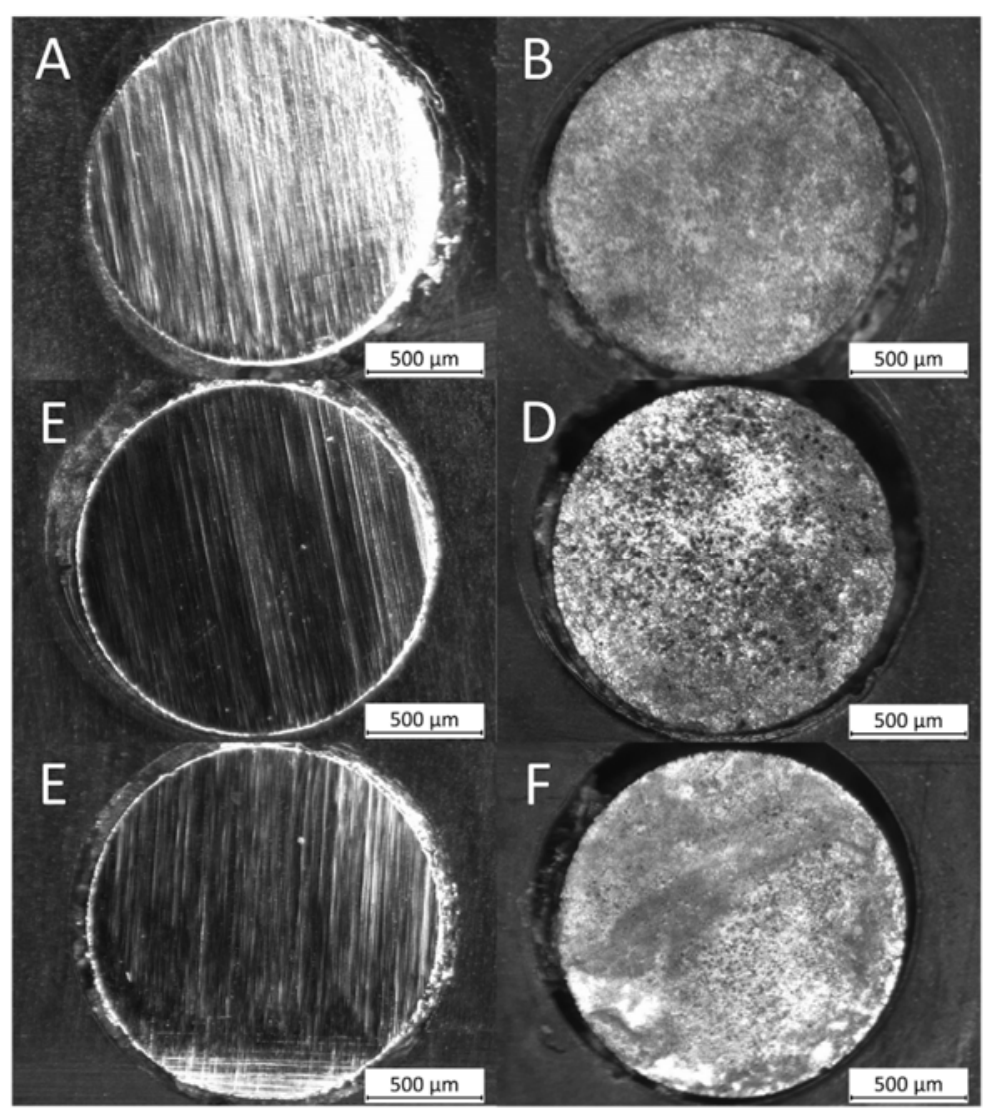

Figure 4. Stereographs of carbon steel surfaces before and after potentiodynamic test in ILs containing water up to their solubility limit: A \& B: before and after test in C4, C \& D: before and after test in C6, E \& F: before and after test in C8 


\section{WILEY-VCH}

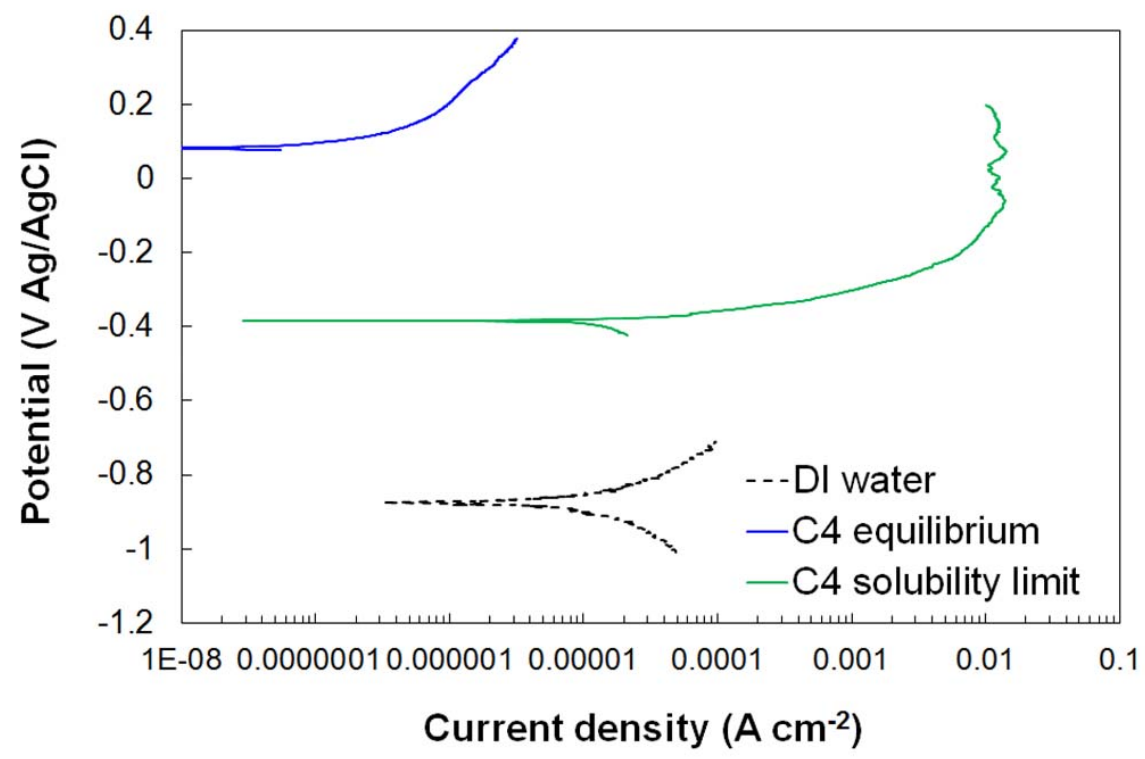

Figure 5. Comparison of potentiodynamic polarization curves of carbon steel in $\mathrm{C} 4$

containing water up to its solubility limit and in equilibrium with the laboratory atmosphere

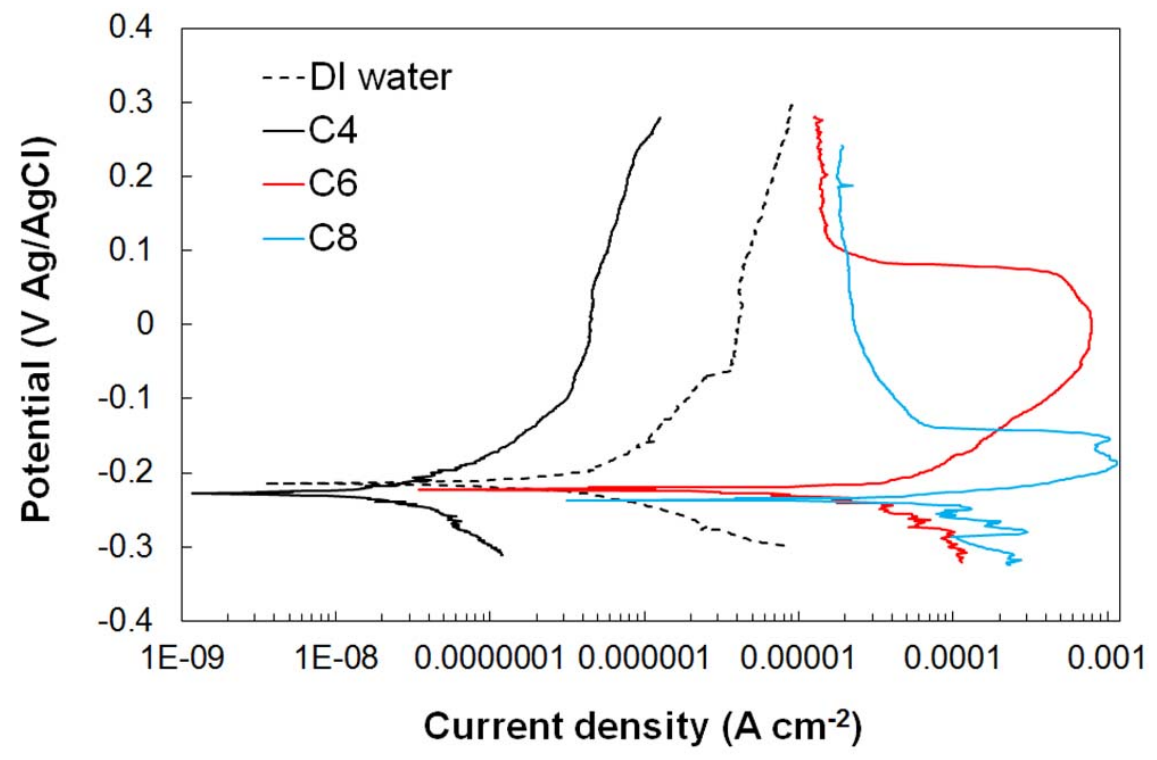

Figure 6. Anodic behavior of stainless steel in ILs containing water up to their solubility limit and in deionized water, at $60^{\circ} \mathrm{C}$ 


\section{WILEY-VCH}

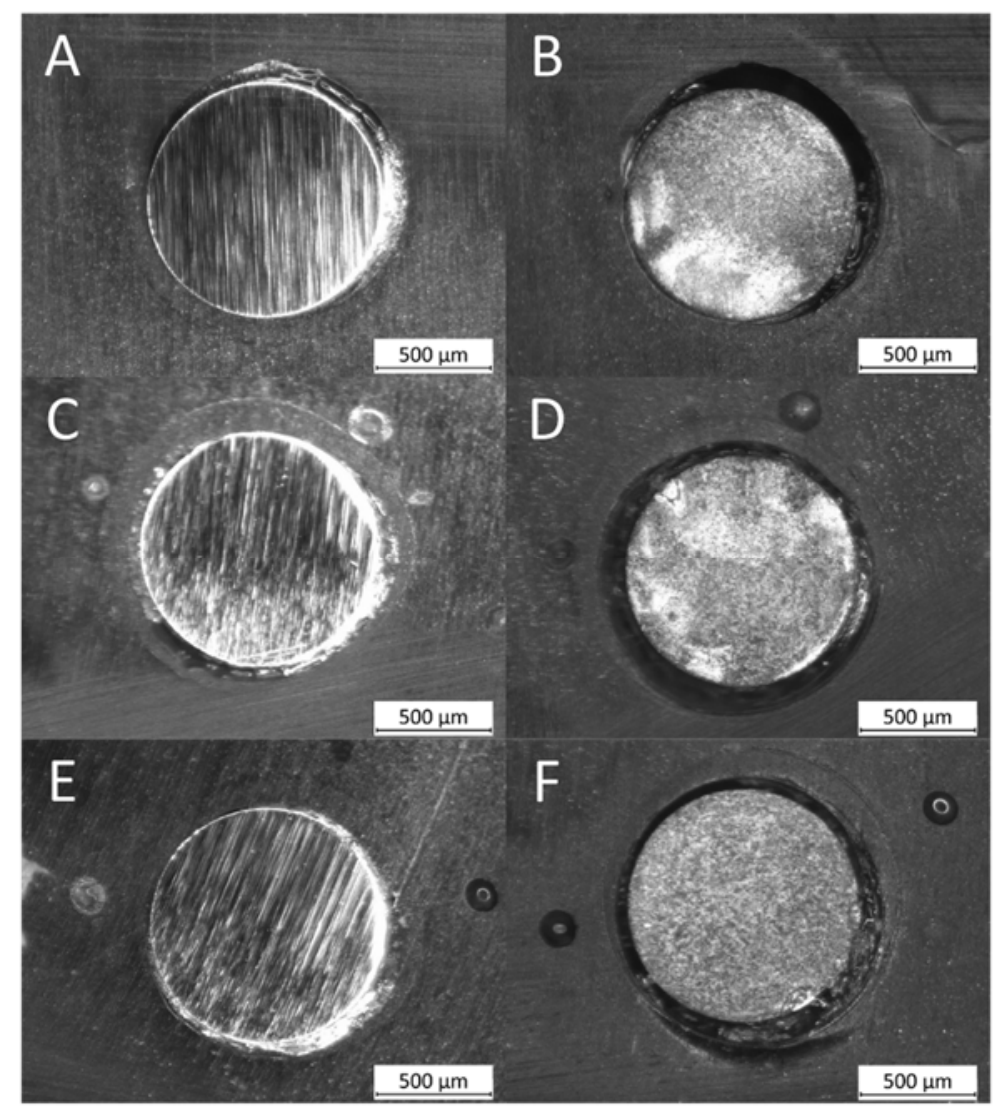

Figure 7. Stereographs of stainless steel surfaces before and after potentiodynamic test in ILs containing water up to their solubility limit: A \& B: before and after test in C4, C \& D: before and after test in C6, E \& F: before and after test in C8

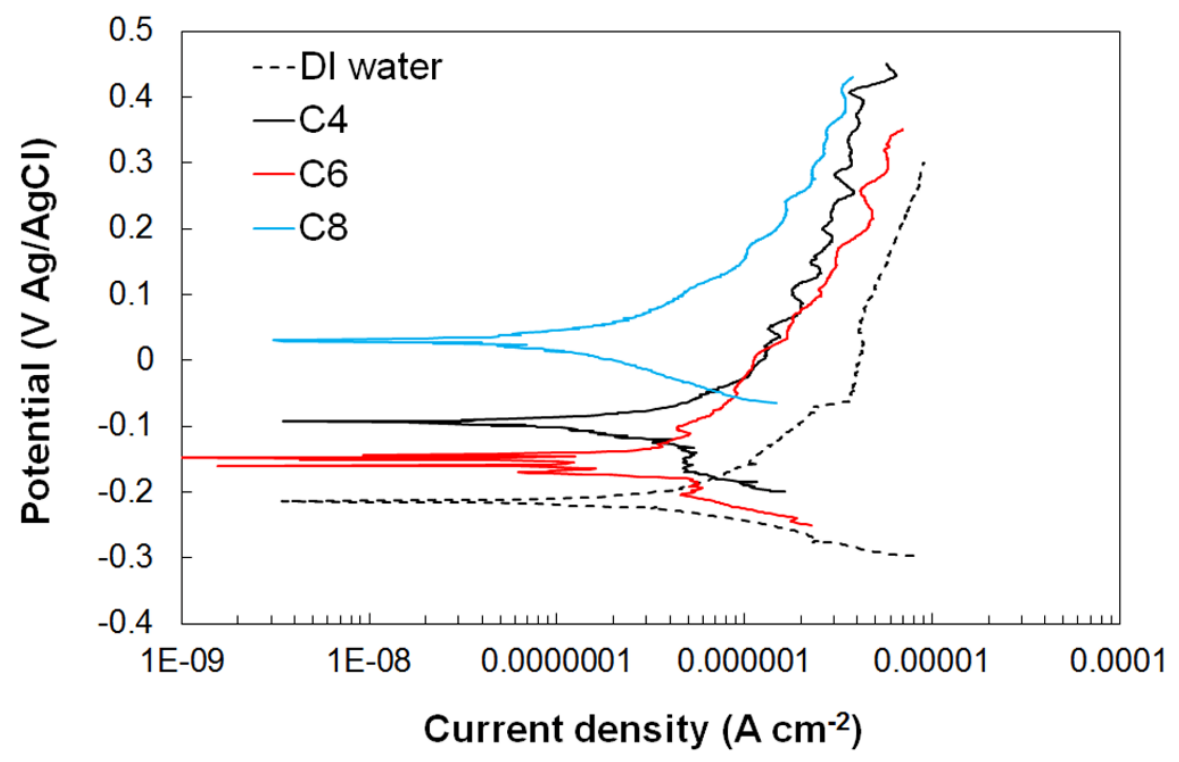

Figure 8. Comparison of potentiodynamic polarization curves on stainless steel in ILs containing excess water and deionized water 


\section{WILEY-VCH}

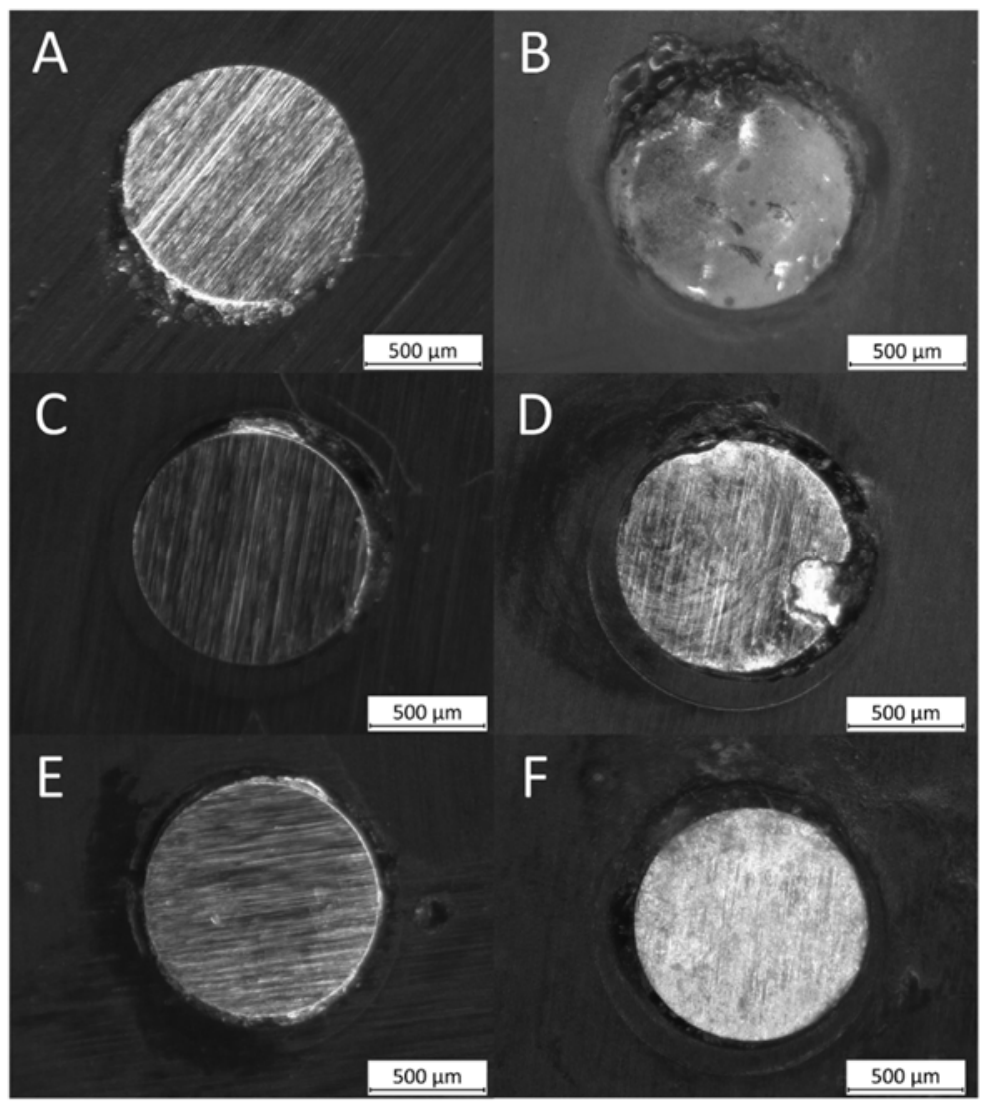

Figure 9. Stereographs of stainless steel sample surfaces before and after the potentiodynamic test in excess water ionic liquid: A \& B: before and after test in C4, C \& D: before and after test in $\mathrm{C} 6, \mathrm{E} \& \mathrm{~F}$ : before and after test in $\mathrm{C} 8$

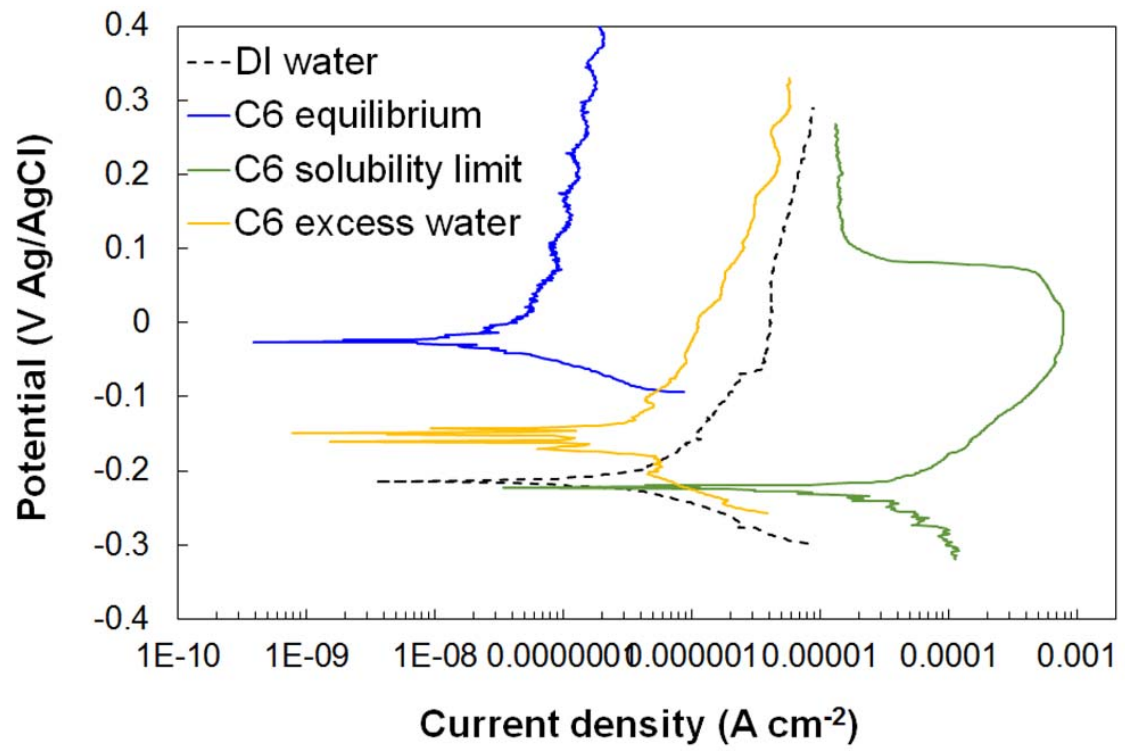

Figure 10. Comparison of potentiodynamic curves of stainless steel in C6 in equilibrium and water solubility limit conditions 


\section{WILEY-VCH}

Equilibrium water content $(<2 \%) \quad$ Water at solubility limit $(2-5 \%) \quad$ Excess water content $(25 \%)$

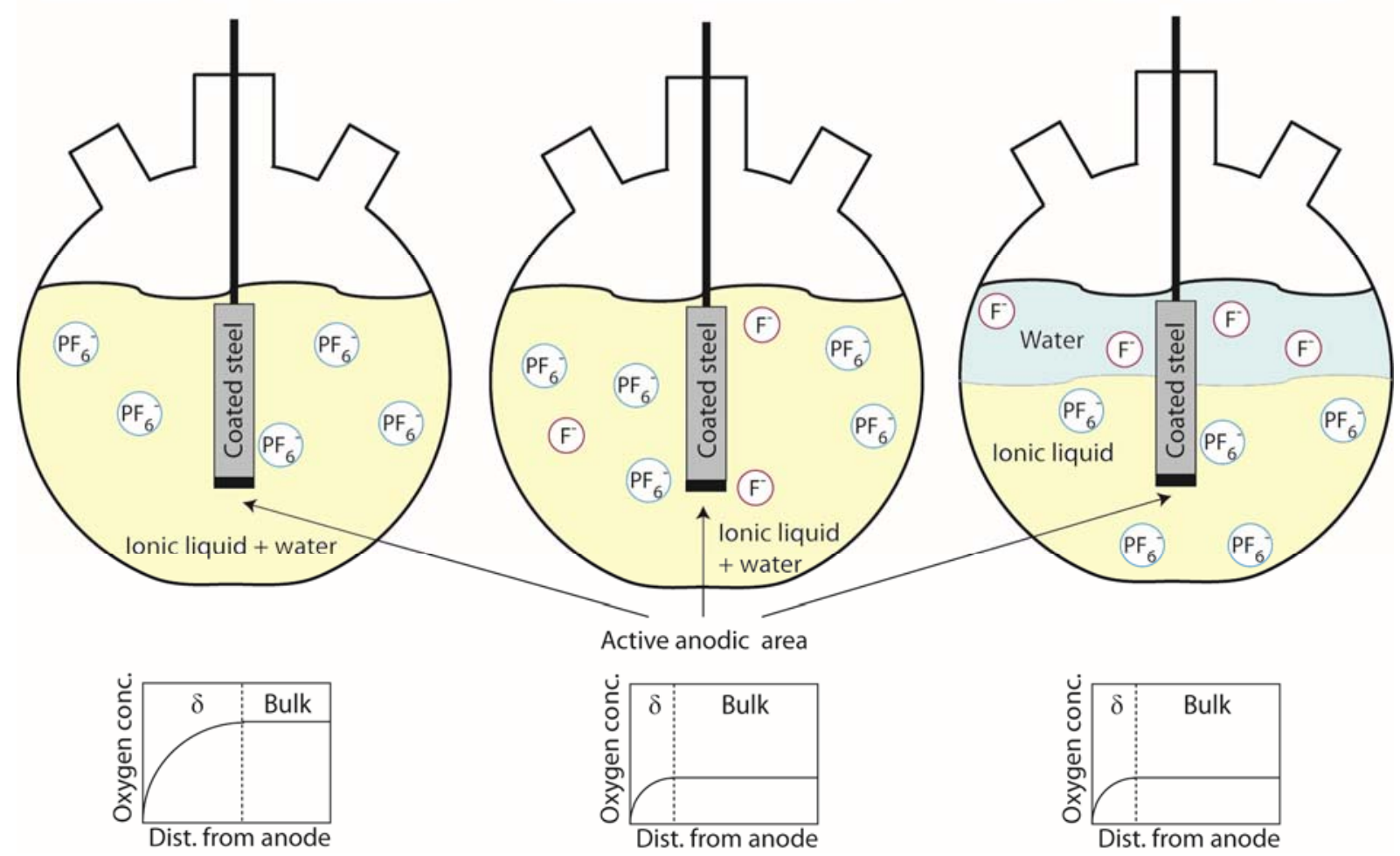

Figure 11. Schematic representation of contact between steel sample and relevant species in the electrolyte in the three conditions of water content tested (equilibrium - low water content, solubility limit - water saturation in IL, excess - water in IL exceeding solubility limit) 
BLACK/WHITE VERSIONS OF COLOR FIGURES

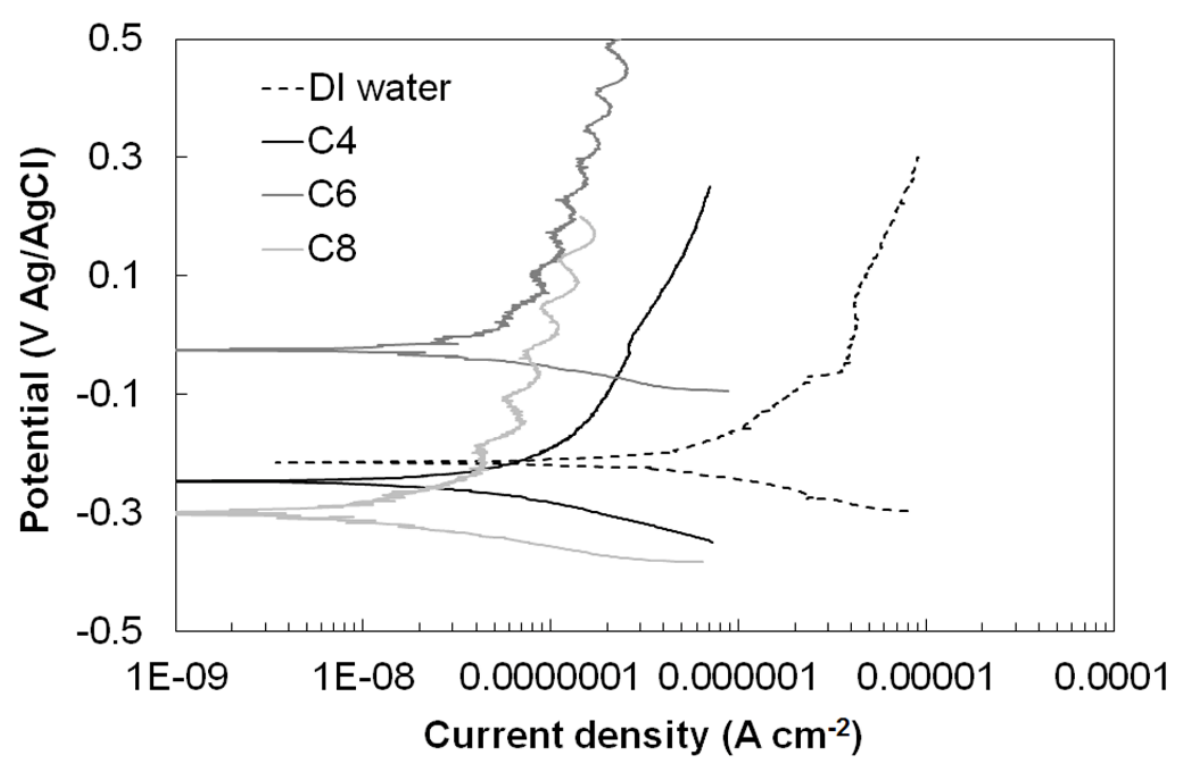

Figure 2

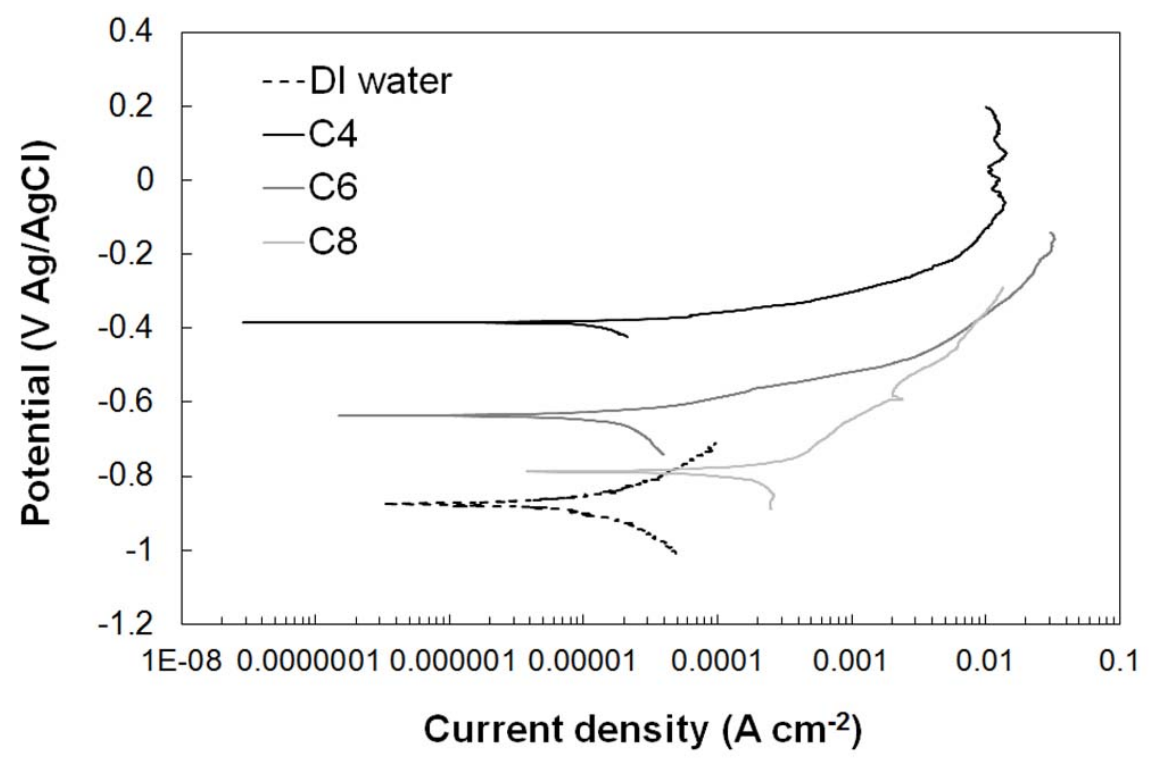

Figure 3 


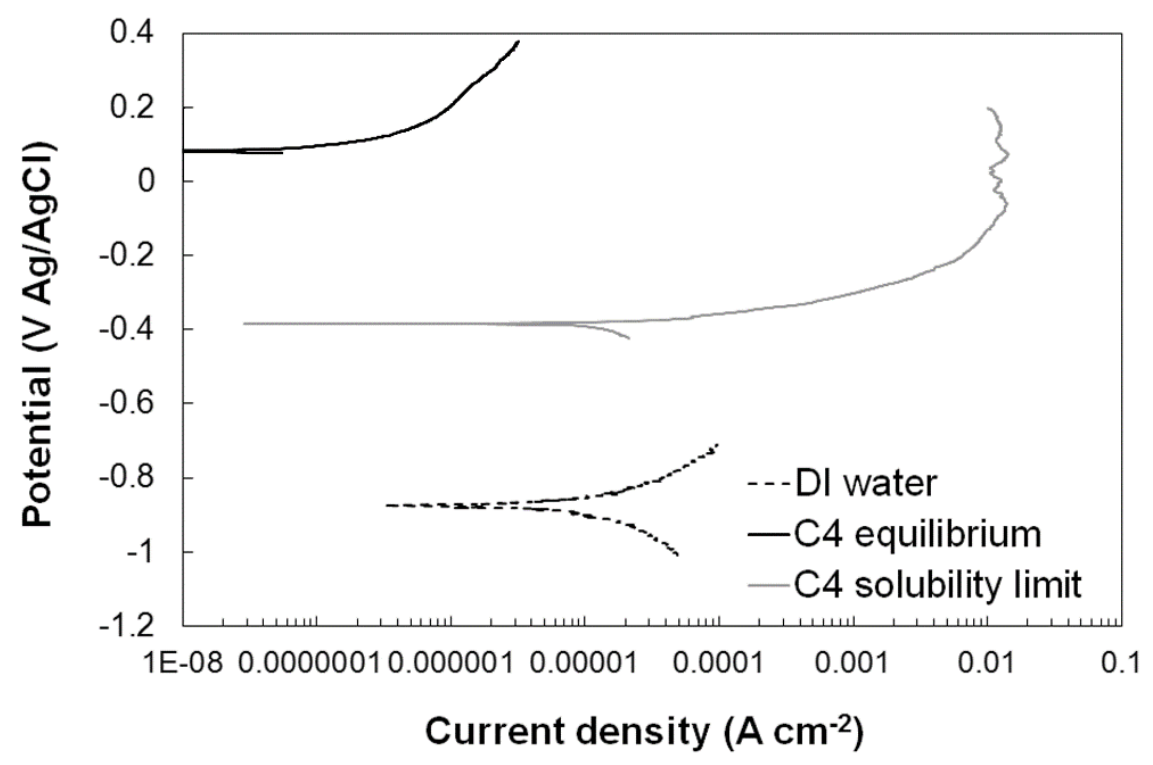

Figure 5

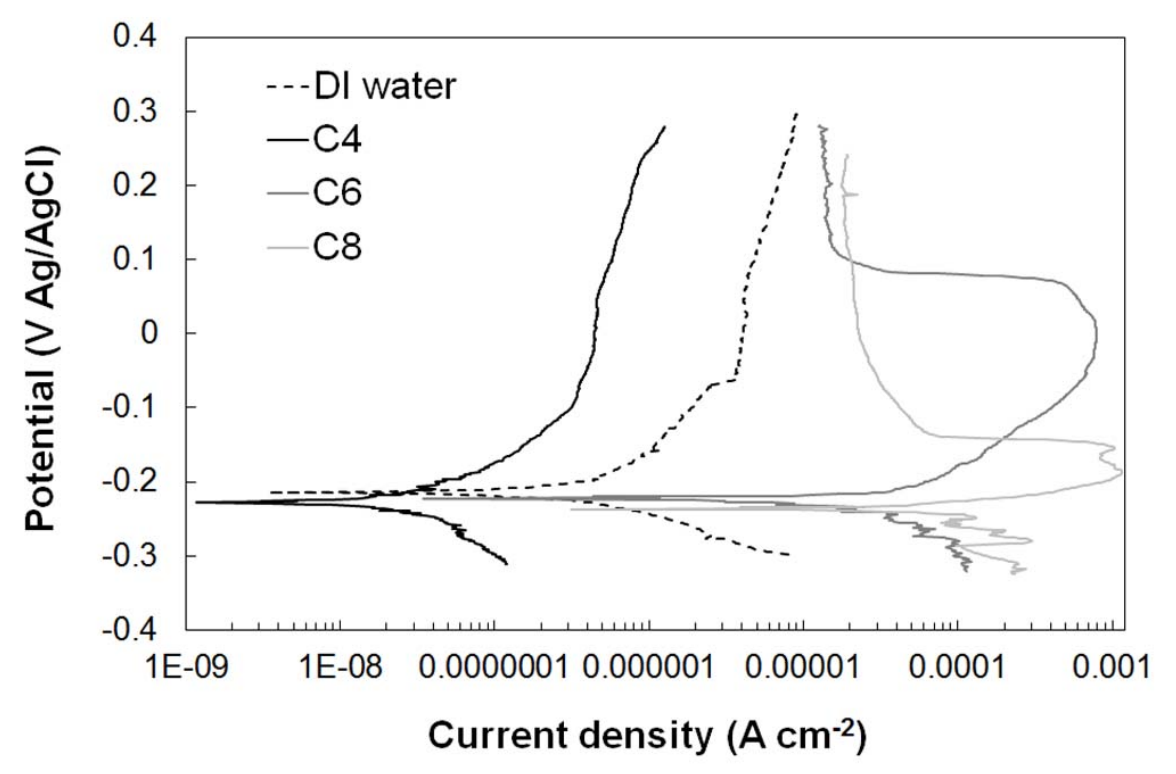

Figure 6 


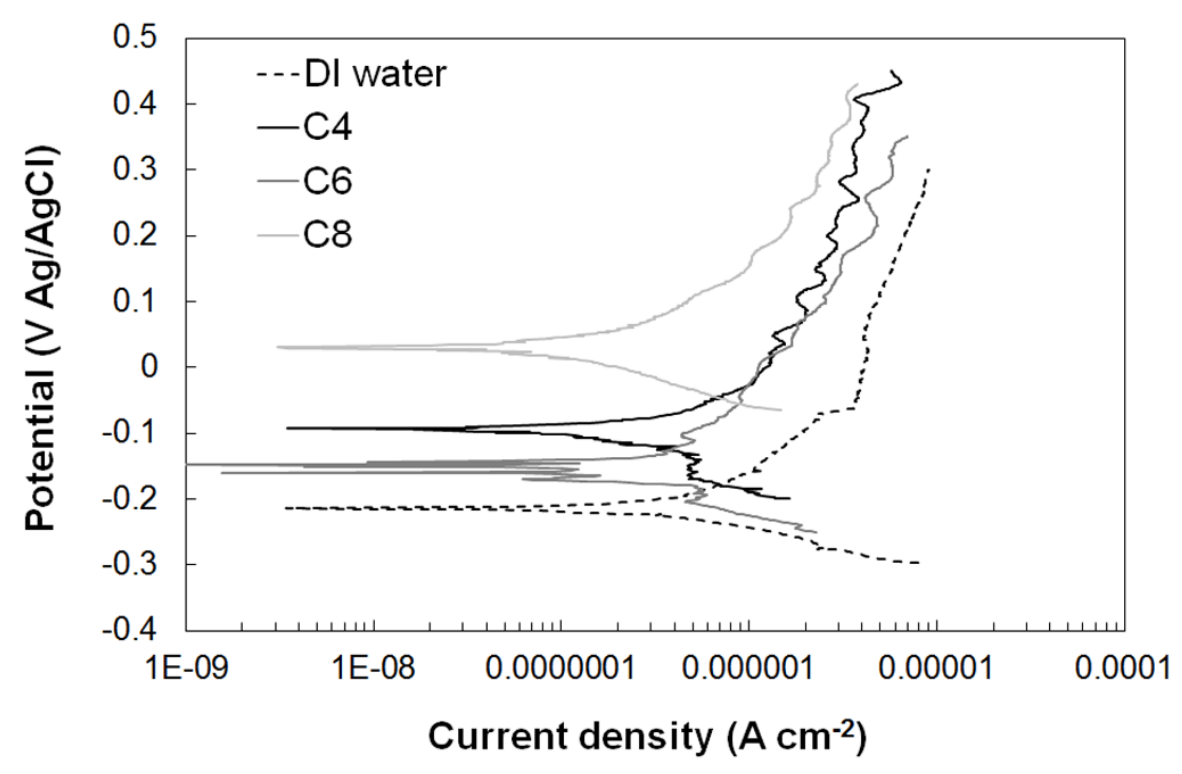

Figure 8

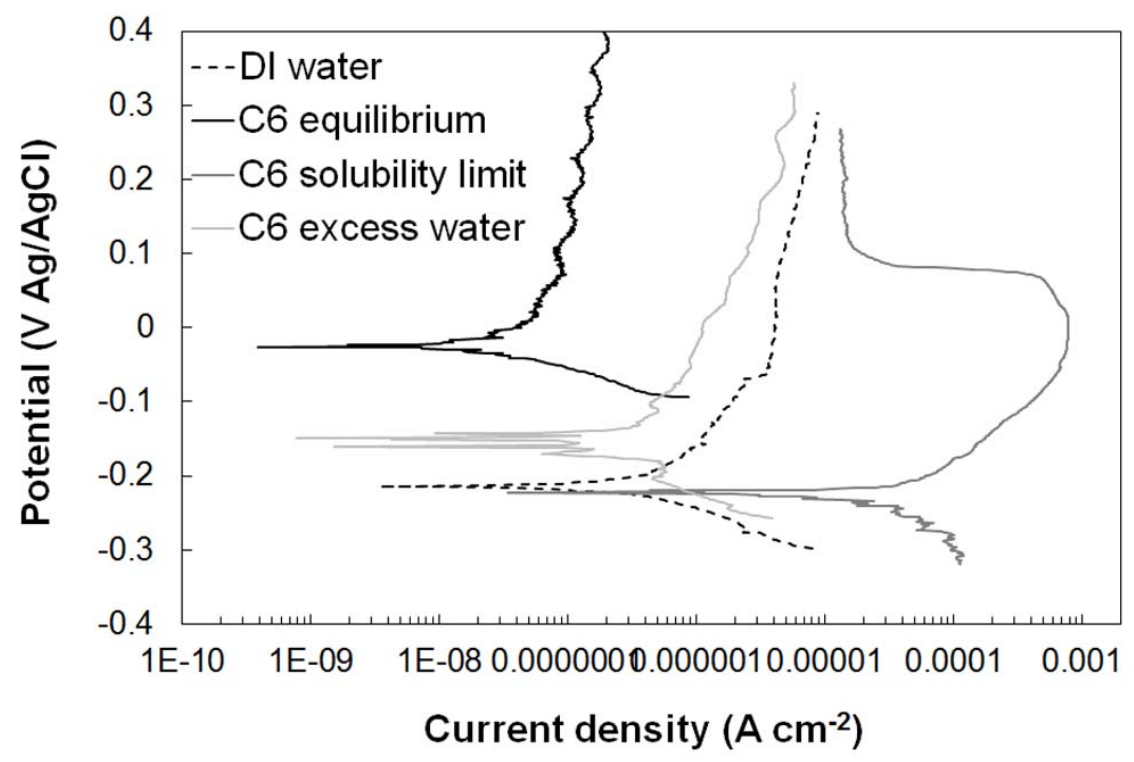

Figure 10 


\section{WILEY-VCH}

Equilibrium water content $(<2 \%) \quad$ Water at solubility limit $(2-5 \%) \quad$ Excess water content $(25 \%)$

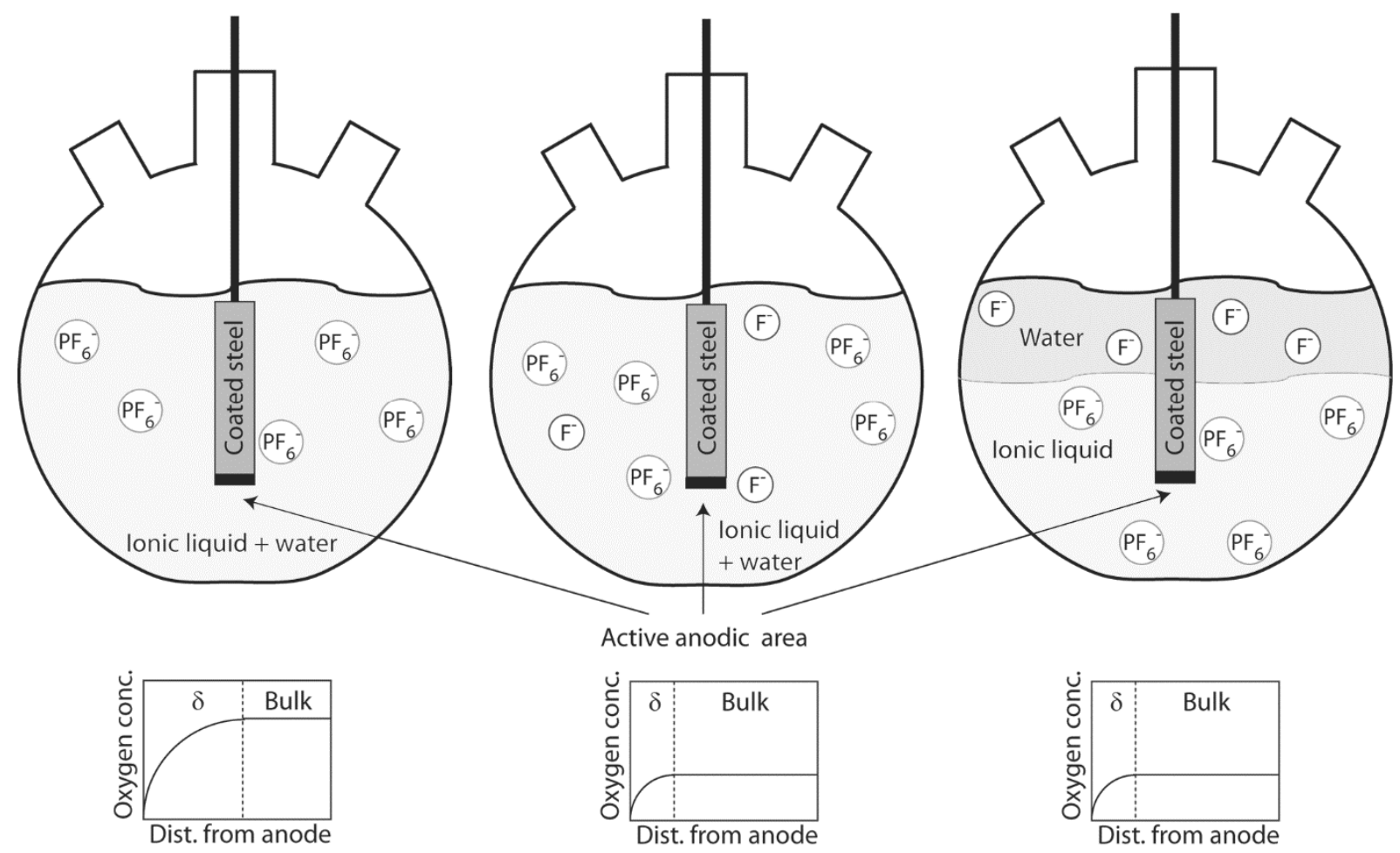

Figure 11 
TABLES

Table 1. Added water in the solubility limit condition (vol\%)

\begin{tabular}{llll}
\hline & {$[\mathrm{C} 4 \mathrm{C} 1 \mathrm{Im}][\mathrm{PF} 6]$} & {$[\mathrm{C} 6 \mathrm{C} 1 \mathrm{Im}][\mathrm{PF} 6]$} & {$[\mathrm{C} 8 \mathrm{C} 1 \mathrm{Im}][\mathrm{PF} 6]$} \\
\hline vol\% of water added & $4.46 \%$ & $3.40 \%$ & $2.06 \%$ \\
\hline
\end{tabular}

Table 2. Composition of steel alloys (wt $\%)$

\begin{tabular}{lllllllll}
\hline & $\mathrm{C}$ & $\mathrm{Si}$ & $\mathrm{Mn}$ & $\mathrm{S}$ & $\mathrm{P}$ & $\mathrm{Cr}$ & $\mathrm{Ni}$ & $\mathrm{Mo}$ \\
\hline UNS S30400 & $<0.08 \%$ & $<0.75 \%$ & $<2.00 \%$ & $<0.03 \%$ & $<0.045 \%$ & $17.8 \%$ & $9.8 \%$ & - \\
& & & & & & & & - \\
\hline UNS G10400 & $<0.39 \%$ & $<0.07 \%$ & $<0.70 \%$ & $<0.04 \%$ & $0.017 \%$ & - & - & - \\
\hline
\end{tabular}

Table 3. Conductivity $\left(\mathrm{S} \mathrm{m}^{-1}\right)$

\begin{tabular}{cccccc}
\hline & {$[\mathrm{C} 4 \mathrm{C} 1 \mathrm{Im}]\left[\mathrm{PF}_{6}\right]$} & {$[\mathrm{C} 6 \mathrm{C} 1 \mathrm{Im}]\left[\mathrm{PF}_{6}\right]$} & {$[\mathrm{C} 8 \mathrm{C} 1 \mathrm{Im}]\left[\mathrm{PF}_{6}\right]$} & DI water & Tap water \\
\hline As received & 0.12 & 0.08 & 0.04 & 0.003 & 0.07 \\
\hline Equilibrium & 0.22 & 0.09 & 0.05 & & \\
\hline $\begin{array}{c}\text { Solubility } \\
\text { limit }\end{array}$ & 0.43 & 0.22 & 0.13 & & \\
\hline Excess water & 0.45 & 0.24 & 0.14 &
\end{tabular}

Table 4. Linear polarization tests data and calculated corrosion rates for carbon steel in ILs containing water up to their water solubility limit

\begin{tabular}{lcccc}
\hline Sample & $\mathrm{R}(\Omega)$ & Surface area $\left(\mathrm{mm}^{2}\right)$ & $\mathrm{R}_{\mathrm{p}}\left(\Omega \mathrm{m}^{2}\right)$ & C.R. $\left(\mathrm{mm} \mathrm{a}^{-1}\right)$ \\
\hline $\mathrm{C} 4$ & 35685 & 1.768 & 0.063 & 0.48 \\
\hline C6 & 24307 & 1.768 & 0.043 & 0.70 \\
\hline C8 & 13736 & 1.768 & 0.024 & 1.27 \\
\hline
\end{tabular}


WILEY-VCH 


\section{WILEY-VCH}

\section{Graphical Abstract}

The corrosion behavior of steels in imidazolium based ILs with $\mathrm{PF}_{6}{ }^{-}$anion indicates that cathodic reaction is oxygen reduction, with different limiting current density depending on water content. $\mathrm{PF}_{6}{ }^{-}$hydrolysis can cause acidification, increasing corrosiveness. Yet, increasing the amount of water a phase separation occurs, reducing IL acidity and increasing corrosion risk in the water phase.
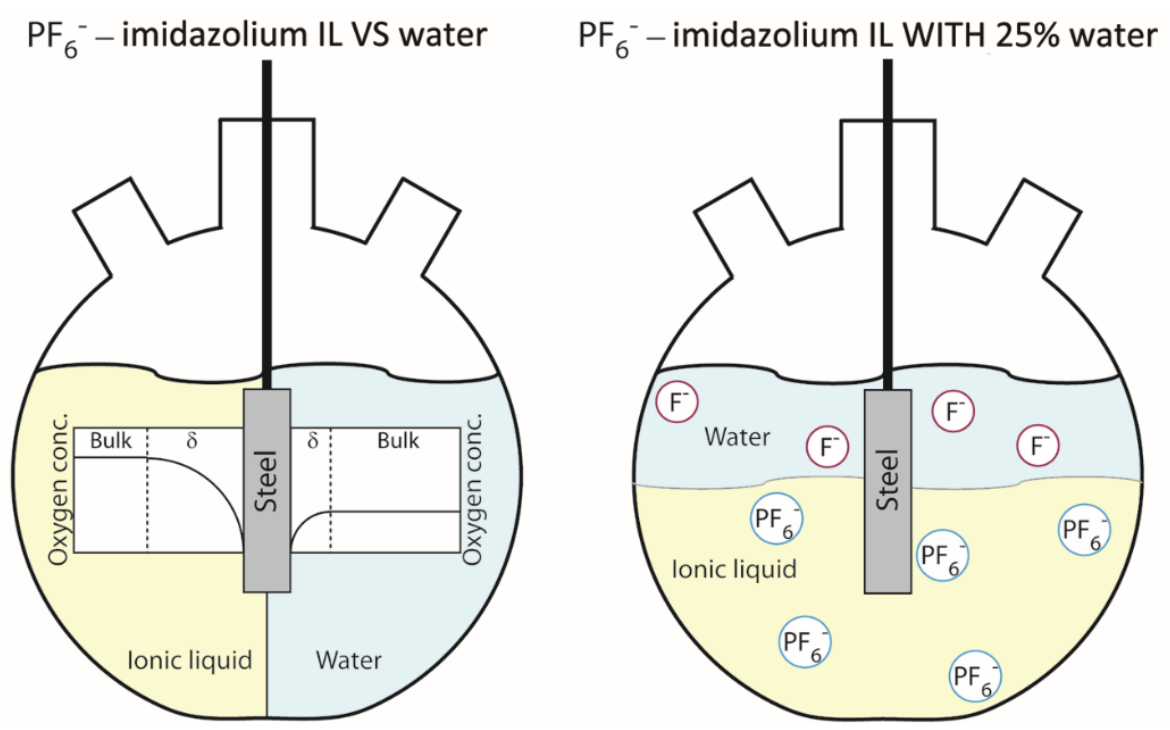